\title{
Proctors in interventional cardiology: go beyond mentoring and monitoring!
}

\begin{abstract}
${ }^{1}$ Department of Cardiology, Manipal Hospital, Bangalore, India

${ }^{2}$ Vikram Hospital, Bangalore, India
\end{abstract}

\section{Correspondence to}

Professor S S Iyengar, Consultant Cardiologist, Manipal Hospital, HAL Airport Road, Bangalore 560017, India; ssiyengar1945@ gmail.com

\author{
S S lyengar, ${ }^{1}$ Girish S Godbole, ${ }^{2}$ V Subashchandra'
}

The last decade has seen exciting advances in interventional cardiology. These innovations have tremendous potential for offering attractive alternatives to the existing surgical treatments of some cardiac diseases and have also identified novel methods of percutaneous intervention for hitherto pharmacologically managed conditions. Many of these advances have been driven by the introduction of implantable devices, such as the percutaneous aortic valve and left atrial appendage closure device.

Introduction of a new technology to physicians as well as adequately training the interventionist in the science and technique of intervention is partly and rightly driven by the device industry. While it is necessary from the point of view of the patients as well as from the business standpoint of the device developer that these devices - and the skills to use these devices - are disseminated widely, ensuring that the right patients get the right interventions by adequately trained interventionists is of utmost importance.

Training an interventionist in the science and technique of a new device or technology should typically go through two phases: preceptorship and proctorship. ${ }^{1}$

Preceptorship involves the 'student' interventionist getting trained by the preceptor $(n$. teacher or instructor) in a setting where the preceptor has the primary responsibility of patient care and outcome.

Once the preceptor is satisfied with the 'student' interventionist's knowledge and competence, he or she moves to proctorship. In this situation, the proctor $(n .1$. An invigilator at a university or college examination. 2. An official charged with various duties, especially with the maintenance of good order) observes and guides the procedure carried out by the 'student' interventionist, and assists if necessary. Here, the 'student' interventionist is primarily responsible for patient care and outcome.

In an ideal scenario, the preceptor and proctor would adequately train the 'student' interventionist and the 'student' would follow the ethics, science, and art of the new technique. However, real world experience would suggest that this is not always the case.

There is no dearth of innovative minds and itchy hands in the field of interventional cardiology, since 'the bold and the bright' usually enter the arena. These minds and hands do innovate and, many times, revolutionise science and technology. However, any useful device or procedure can be misused, often to the detriment of the patient and society at large. Therein lies the Achilles' heel of interventional cardiology.

The device industry plays a major role in enabling preceptorship and proctorship for training the interventionist. However, understandably, there is a commercial interest behind promoting the use of the products and techniques. ${ }^{2}$ It is incumbent upon the interventional cardiology community to ensure that the right patient gets the right intervention.

Do we have a mechanism which ensures that patients are protected from trigger happy interventionists and inappropriate interventions? Do we need formal guidelines for 'preceptorship' and 'proctorship'? Is regulation required? The answer is, arguably, 'yes'. 3

In a resource-scarce world, it is important to ensure that aggressive and expensive interventions are carried out appropriately, lest it compromise the patient's interests. Also, the trust deficit that exists in many parts of the world between the medical profession and society at large would only widen with inappropriate interventions; therefore, every effort should be made to prevent them.

Preceptorship, perhaps, does not require intensive monitoring or regulation. Since the preceptor carries out the intervention presumably under strict regulations that govern the use of new devices and technologies, and is primarily responsible and liable for the patient's outcome, the scope for misuse is relatively limited.

Proctorship, however, is a completely different ballgame. The 'student' interventionist is eager to use the new technology/device he or she has trained for. The device manufacturer is keen that its product is used in a new country or centre. The proctor typically flies in and out for the procedure and has no direct liability for the patient's outcome. In this type of scenario, the potential for inappropriate use of the new device or technology exists.

How can the proctor make a difference? As things stand, in the real world, a proctor would function in one of two ways:

Scenario 1: The proctor arrives at the hospital, obtains all the relevant clinical details first-hand from the 'student' interventionist, interacts with the patient and sees all the relevant laboratory reports and images, and is satisfied that the indication and the technical requirements for the procedure are met. Only then does he proceed to guide and observe the procedure, and assists where required. In other words, he is practically a part of the 'Heart Team', minus the legal liability. On the other hand, after his interaction with the patient and the interventionist on site, if the proctor feels that the 


\section{Viewpoints}

procedure should not be carried out, he advises the 'Heart Team' and the patient accordingly, and ensures that the intervention does not take place on his watch.

Scenario 2: The proctor flies in, has no contact with the patient, gets immersed in the 'images' and technical aspects of the case, observes the procedure, assists if necessary - and leaves in a hurry.

The latter scenario is clearly not desirable. We believe that the proctor should not be merely a super-technician who has no role at all in the overall care of the patient. Undoubtedly, the interventionist whom the proctor is observing is primarily responsible for the care of the patient and the proctor cannot assume legal liability. However, as a senior and more experienced cardiologist, the proctor is ethically and morally bound to ensure that the indication and patient selection for the procedure is appropriate.

We believe that a good proctor should be a benevolent mentor as well as a strict invigilator.

Preceptors and proctors are necessary in the rapidly advancing field of interventional cardiology to teach, train, supervise, and observe those interested in learning and carrying the science forward in the right direction. However, considering the potential for misuse of new devices and technologies, there is a need to have guidelines for interventionists and their proctors from professional societies and regulatory agencies of the respective countries. This is particularly relevant to lower and middle income countries to ensure appropriateness of these complex and expensive interventions.

Implicit in the practice of interventional cardiology is intellectual honesty integrated with sound science. It is important to always remember that.

Contributors All three have equally contributed to conceptualisation and writing.

Competing interests None declared.

Provenance and peer review Not commissioned; externally peer reviewed.

(c) Article author(s) (or their employer(s) unless otherwise stated in the text of the article) 2017. All rights reserved. No commercial use is permitted unless otherwise expressly granted.

\section{REFERENCES}

1 Glauber M, Murzi M, Cerillo AG. Is proctoring mandatory when starting a TAVI program? Ann Cardiothorac Surg 2012;1:190-3.

2 Thomas M. Interventional cardiology and the medical devices industry: is there a conflict of interest? Heart 2007;93:1351-2.

3 Herrmann HC, Baxter S, Ruiz CE, et al. on behalf of the SCAI Council on Structural Heart Disease. Results of the Society of Cardiac Angiography and Interventions survey of physicians and training directors on procedures for structural and valvular heart disease. Catheterization and Cardiovascular Interventions 2010;76:E106-10. 